XIV Simpósio Nacional de Sistemas Prediais

Gestão, Eficiência e Sustentabilidade

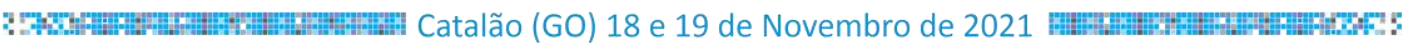

\title{
VIABILIDADE ECONÔMICA DE SISTEMA PARA REDUÇÃO DO DESPERDÍCIO DE ÁGUA EM SISTEMAS PREDIAIS DE ÁGUA QUENTE: UM ESTUDO DE CASO EM EDIFICAÇÕES MULTIFAMILIARES
}

\author{
Economic feasibility of a system to reduce waste of water in hot water \\ building systems: a case study in multifamily buildings
}

IORIS, Marcelo Dalmédico; ; GHISI, Enedir²

Recebido em 15 de julho de 2021, aprovado em 06 de setembro de 2021, publicado em 18 de novembro de 2021

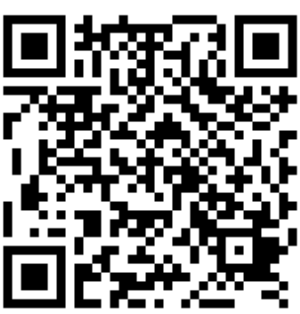

Palavras-chave:

Aquecedor de passagem a gás,

Economia de água,

Reservatório inferior de água não potável,

Água fria,

Água quente.

Keywords:

Instantaneous gas

heater,

Water savings,

Non-potable water storage tank,

Cold water,

Hot water.
RESUMO: Em residências que possuem aquecedores de passagem a gás para o aquecimento da água, há desperdício de água no início da utilização dos aparelhos sanitários. O objetivo deste trabalho é verificar a viabilidade econômica ao implementar um sistema automatizado nos pontos de consumo de água quente das edificações que reduz o desperdício de água dos instantes iniciais de uso. Realizou-se análise econômica comparativa entre a instalação do sistema automatizado proposto e de um sistema de recirculação individual em um estudo de caso para um edifício multifamiliar. Foram realizadas nove análises econômicas diferentes variando-se o potencial de economia de água e o tipo de sistema para obter o Valor Presente Líquido, a Taxa Interna de Retorno e o payback descontado. As análises comprovaram que o sistema proposto é mais viável que os sistemas de recirculação individual usualmente empregados. O sistema proposto reduz o desperdício de água se mostrando viável ao proporcionar um potencial diário de economia de água de pelo menos 5,6\%. O emprego do sistema depende da existência de sistema de aquecimento afastado dos pontos de consumo e da presença de um reservatório inferior. Custos de instalação devem ser cautelosamente orçados para que o sistema se mostre viável economicamente.

ABSTRACT: In dwellings that have instantaneous gas heaters to heat water, cold water is wasted in the first seconds of using hot water fixtures. The objective of this work is to verify the economic feasibility of implementing an automated system integrated to the hot water fixtures of buildings that reduces the waste of water from the initial moments of use. A comparative economic analysis between the installation of the proposed automated system and an individual recirculation system was performed for a case study for a multifamily building. Altogether nine different economic analyses were carried out, varying the water saving potential and the type of recirculation system to obtain the Net Present Value, Internal Rate of Return and discounted payback. It was verified in all analyses that the proposed system is more viable than the traditionally used individual recirculation system. The proposed system reduces waste of water in domestic hot water systems, proving viable by providing a daily water savings potential of at least $5.6 \%$. The use of the system depends on the existence of a heating system away from the water fixtures and the presence of an underground water tank. Costs for installation-related services must be carefully budgeted for the system to be economically feasible.

\section{CONTATO DOS AUTORES:}

${ }^{1}$ IORIS, Marcelo Dalmédico: Universidade Federal de Santa Catarina, marcelo.ioris@posgrad.ufsc.br

${ }^{2}$ GHISI, Enedir: Universidade Federal de Santa Catarina, enedir.ghisi@ufsc.br 


\section{INTRODUÇÃO}

Em residências que possuem aquecedores de passagem a gás para o aquecimento da água sem apoio de sistemas de recirculação, há desperdício de água nos segundos iniciais da utilização dos aparelhos sanitários (GONÇALVES et al., 1989; LUTZ, 2005; CHAGURI JUNIOR, 2009; LUTZ, 2011; SHERMAN, 2014; WOOD; D'ACQUISTO, 2015; IORIS; GHISI, 2021). A NBR 5626 (ABNT, 2020a) orienta que o sistema de distribuição de água quente deve ser dimensionado reduzindo-se ao máximo o tempo de chegada de água quente do ponto de aquecimento até o aparelho sanitário mais distante com consumo de água quente. $A$ NBR 13103 (ABNT, 2020b) recomenda que a instalação dos aparelhos convencionais de aquecimento a gás seja feita em locais com adequada ventilação. Esta recomendação faz com que as residências sejam projetadas de modo que os aparelhos sejam instalados nas áreas de serviço ou externamente às edificações. Consequentemente, esta conformação comumente resulta em grandes comprimentos de tubulação de água quente entre a fonte aquecedora e os aparelhos sanitários.

Quando comparados ao chuveiro elétrico, sistema mais utilizado no Brasil atualmente como forma de aquecimento da água, os sistemas residenciais de aquecimento de água a gás possuem elevado custo inicial de instalação. Deste modo, para que esses sistemas não acarretem em despesas e sejam eficazes ao fornecer água quente é de grande importância que haja um sistema integrado de recirculação de água, associado ou não com isolamento térmico das tubulações, que seja viável economicamente.

O objetivo deste trabalho é verificar a viabilidade econômica da implementação de um sistema automatizado integrado aos pontos de consumo de água quente das edificações que elimine o desperdício de água fria dos instantes iniciais de uso.

\section{MÉTODO}

O funcionamento do sistema automatizado para evitar desperdício de água fria nos instantes iniciais da utilização de água quente resume-se na abertura de uma válvula solenoide localizada no final do ramal do sistema predial de água quente da residência. Esta válvula tem a função de direcionar para um reservatório de água não potável a quantidade aproximada de água fria que seria desperdiçada em um determinado aparelho. Por meio de um sinal de radiofrequência enviado ao se acionar um botão próximo ao ponto de consumo de água quente desejado, o sistema reconhece qual ponto de consumo foi acionado e a quantidade aproximada de água fria que deve liberar por meio da válvula até que ocorra a chegada da água quente do aquecedor.

A Figura 1 ilustra a planta de um sistema predial de água fria e água quente. Em edificações multifamiliares com aquecimento da água por meio de aquecedores de passagem a gás, normalmente os pontos são abastecidos por um ramal de água fria conectado ao reservatório da edificação, e outro ramal de água quente conectado ao aquecedor de passagem. 
Figura 1 - Planta de sistema usual de água fria e água quente

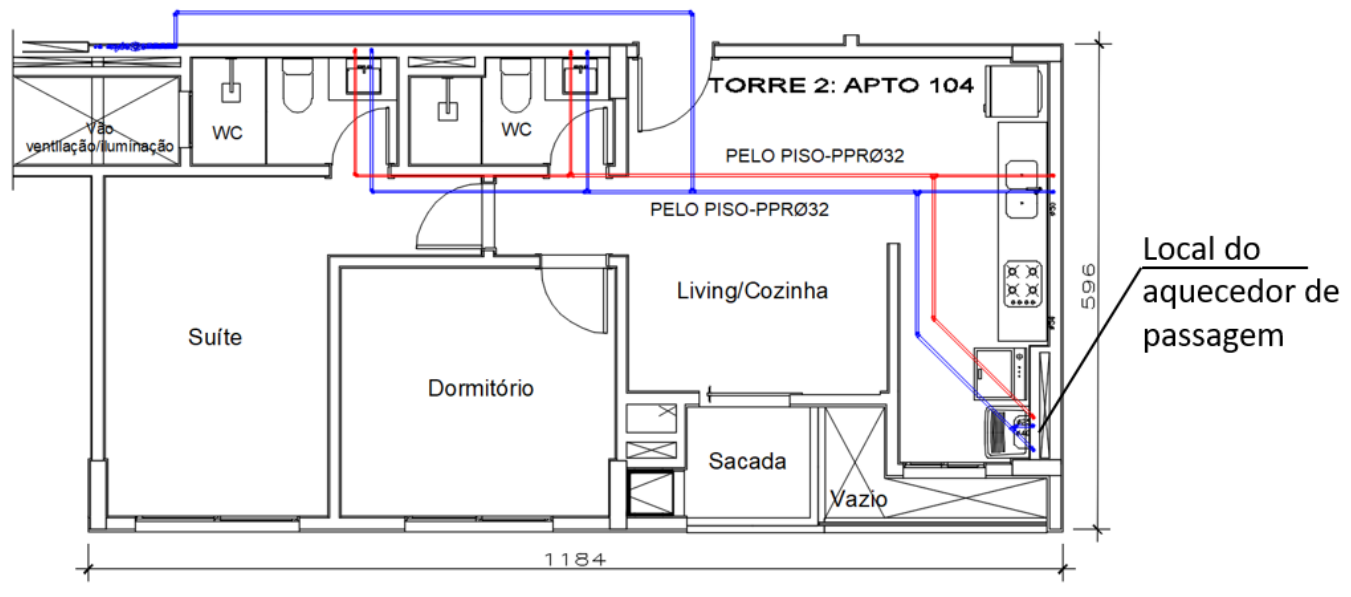

Fonte: Ioris; Ghisi (2020).

Para uma melhor eficiência, a conformação do sistema automatizado em uma residência deve ser realizada de modo que as tubulações de água quente passem o mais próximo possível dos pontos de consumo de água. A Figura 2 ilustra como deveria ser a disposição das tubulações na planta da Figura 1.

Figura 2 - Planta do sistema proposto de água fria e água quente

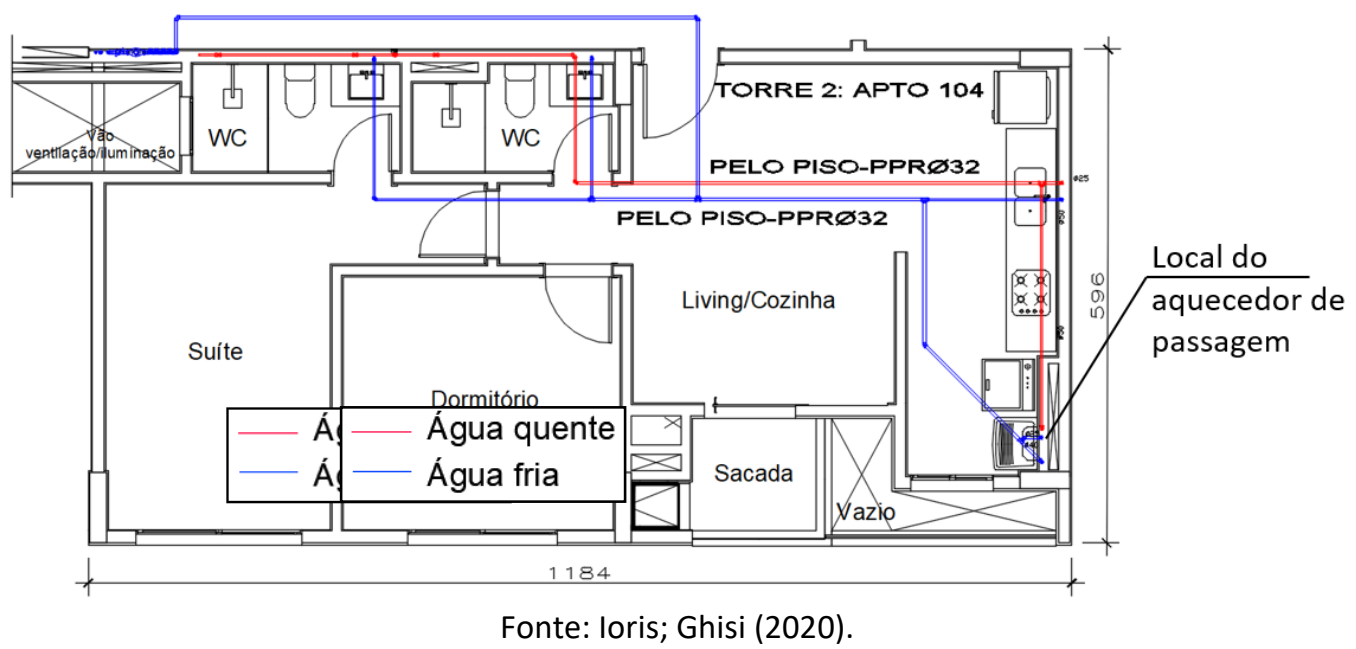

Os botões de acionamento que enviam o sinal de radiofrequência devem ser instalados próximos aos registros de pressão de água quente. Próximo ao ponto de consumo de água quente mais afastado do aquecedor, o sistema deve possuir uma válvula solenoide. E deve haver o sistema de coleta de água dos pontos de consumo da residência, que será análogo aos componentes de um sistema predial de esgoto sanitário. Primeiro deve haver uma tubulação análoga aos ramais de descarga, que coleta a água que passa pela válvula solenoide. Essa tubulação será conectada a uma tubulação vertical, responsável por coletar a água de todas as unidades habitacionais e direcioná-la ao reservatório inferior de água não potável da edificação.

Os diâmetros das tubulações que direcionam a água para o reservatório inferior de água não potável dependerão da quantidade de pontos de consumo de água quente da edificação. 
Todas as demais recomendações feitas pela NBR 5626 (ABNT, 2020a) para o funcionamento correto do sistema predial de distribuição devem ser seguidas para a instalação do sistema de coleta de água do sistema automatizado proposto.

A Figura 3 ilustra um esquema sem escala dos circuitos eletrônicos que ficariam embutidos na alvenaria. O botão próximo ao aparelho de consumo de água quente é conectado a um microcontrolador Arduino que se conecta a um transmissor do módulo de radiofrequência. 0 transmissor, portanto, envia a informação de tempo de abertura da válvula solenoide para o receptor que está conectado a outro microcontrolador Arduino que está conectado também com a válvula solenoide. O receptor recebe o pacote de informações do transmissor, transfere as informações para o Arduino, que por sua vez comanda a abertura da válvula solenoide.

Figura 3 - Circuito eletrônico da ideia proposta.

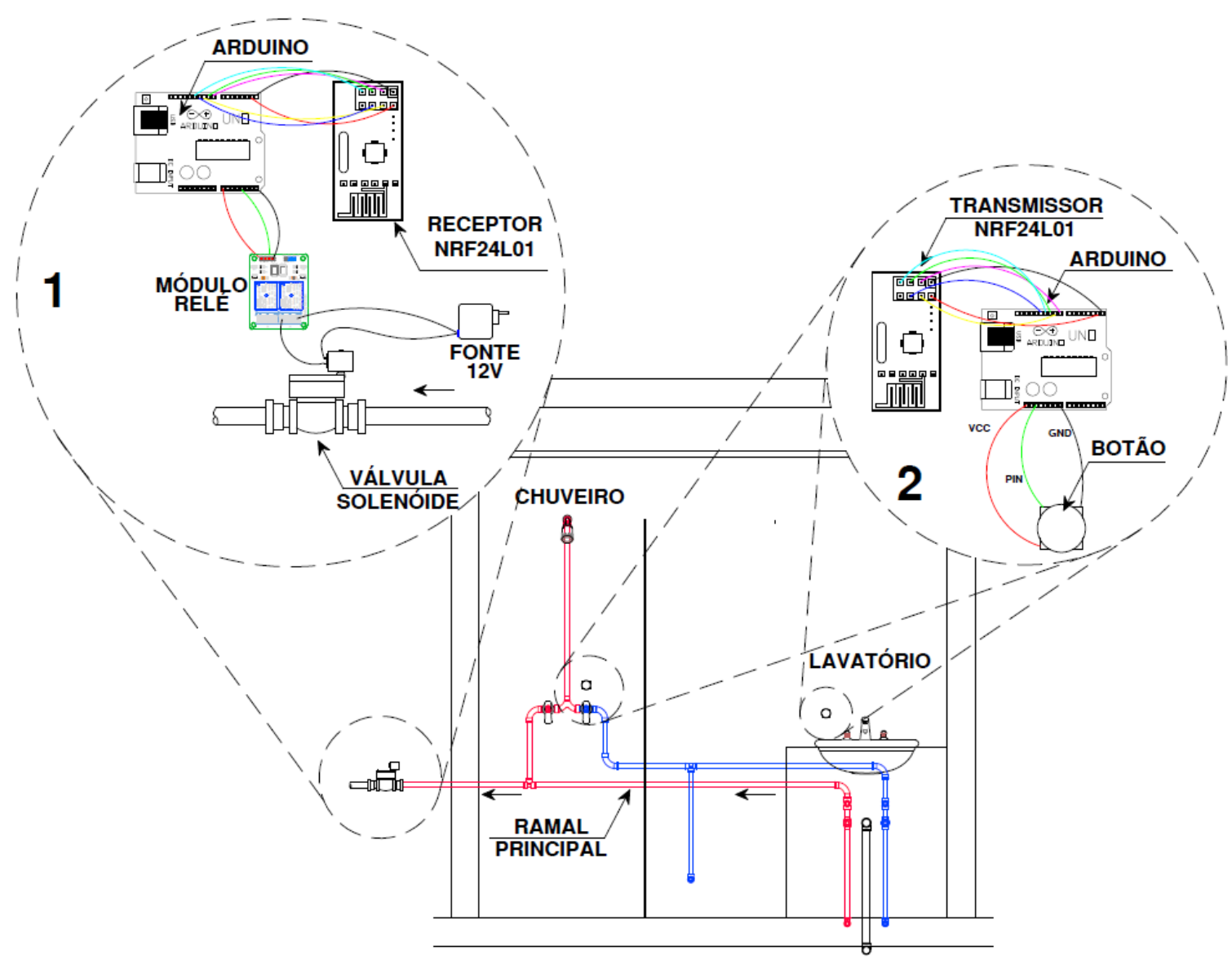

Fonte: Ioris; Ghisi (2020).

Para sinalizar ao usuário que se deve iniciar a abertura do registro de água quente do ponto de consumo, o Arduino acionará uma lâmpada LED verde que indicará que toda a água fria foi escoada da tubulação em direção ao reservatório inferior.

Para avaliar a viabilidade econômica do sistema automatizado proposto para os sistemas prediais foi realizada uma análise comparativa de viabilidade econômica entre a instalação de um sistema de recirculação individual e a instalação do sistema de recirculação proposto neste trabalho. Ambas as instalações foram configuradas, como estudo de caso, para o mesmo edifício multifamiliar, entretanto, em projetos separados. A análise é composta pelo investimento inicial da implantação dos sistemas, custos com manutenção e operação e 
receita total com a economia de água que os sistemas proporcionam durante um horizonte de tempo de dez anos.

Para prever os custos iniciais com instalações hidráulicas para todo o sistema em uma edificação, foram utilizados como base os projetos arquitetônico e hidrossanitário multifamiliar do Edifício Palmas Central, ilustrado na Figura 4.

\section{Figura 4 - Vista tridimensional do Edifício Palmas Central.}

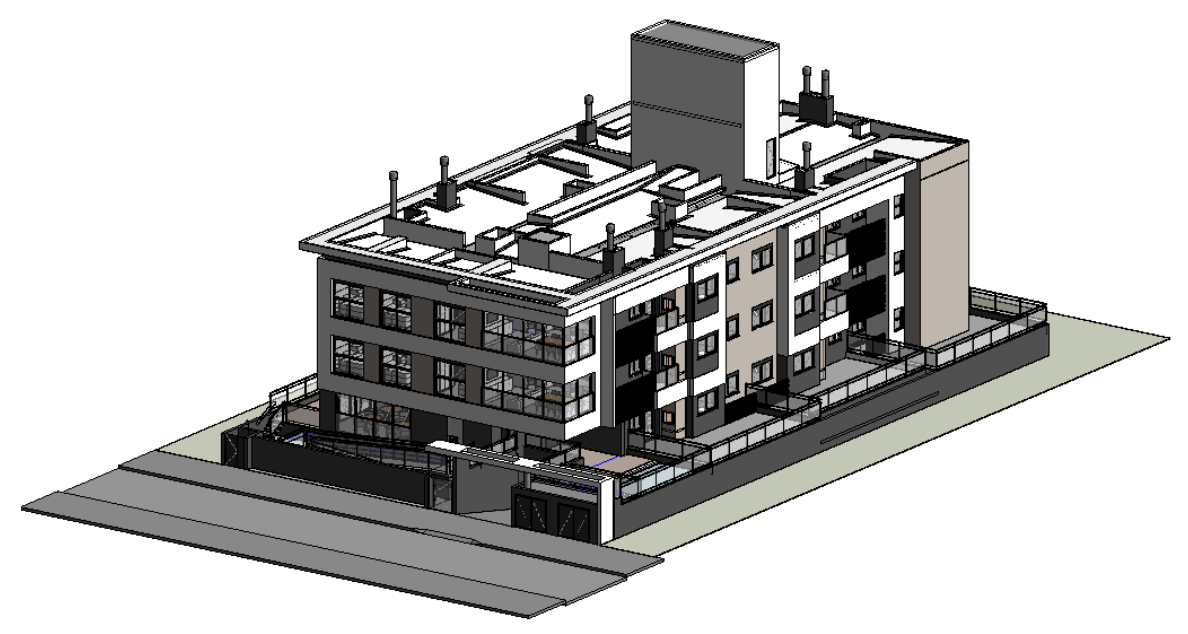

Fonte: Os autores.

O sistema de recirculação individual é caracterizado por possuir uma tubulação de retorno que conecta o final do ramal principal de água quente de volta ao aquecedor de passagem da unidade habitacional.

Para cada apartamento do Edifício Palmas Central foram necessários:

- tubulação e conexões PPR adicionais para retornar o ramal principal de água quente ao aquecedor de passagem;

- isolamento da tubulação de água quente;

- uma eletrobomba de recirculação;

- um painel de comando digital com termostato.

E para o sistema de recirculação proposto, para cada apartamento do Edifício Palmas Central, foram necessários:

- tubulação e conexões PPR adicionais para encaminhar a água fria, que seria desperdiçada, para o reservatório inferior da edificação;

- uma válvula solenoide;

- um microcontrolador;

- um botão de acionamento para cada aparelho sanitário;

- um módulo relé;

- uma fonte de $12 \mathrm{~V}$;

- fios condutores;

- um receptor de radiofrequência;

- um transmissor de radiofrequência por cômodo com consumo de água quente. 
O custo inicial total para a instalação dos sistemas em todo o edifício é a soma do custo total com materiais e do custo total com mão de obra acrescido de $25 \%$ de BDI (Benefícios e Despesas Indiretas).

Para obter o custo com a operação dos sistemas de recirculação deve-se multiplicar o consumo energético mensal pela tarifa praticada pela CELESC (Centrais Elétricas de Santa Catarina) no mês analisado. Os custos com manutenção englobam os gastos ao longo do horizonte de análise para manter os sistemas íntegros e em pleno funcionamento.

Ao todo, três cenários de potencial de economia de água por meio dos sistemas de recirculação foram calculados conforme a demanda por recirculação. A demanda por recirculação foi estimada por meio do ciclo diário e da frequência de uso de água quente por meio dos aparelhos sanitários.

A frequência de uso de água quente, principalmente para torneiras, baseou-se no relatório de uso final de água nas residências para os países da América do Norte. De acordo com o relatório de uso final de água nas residências para os países da América do Norte, $13 \%$ dos eventos de consumo de água por meio de torneiras são realizados com água quente. De acordo com DeOreo e Mayer (2014), há uma frequência de vinte usos de torneira/pessoa.dia, portanto, a frequência de utilização para o cálculo de economia de água por meio de torneiras será de 2,6 usos de torneira com água quente por pessoa por dia. 0 último relatório da Pesquisa de Posse e Hábitos de Uso de Equipamentos Elétricos na Classe Residencial (ELETROBRAS, 2019) indica que em média as residências brasileiras possuem 3,5 habitantes e que a média do número de vezes por dia que o chuveiro é utilizado é 3,95 . Portanto, para a utilização de água quente por meio do banho foi considerada uma frequência de um banho por pessoa por dia. A receita total com economia de água foi calculada por meio da tarifa de água da Companhia Catarinense de Águas e Saneamento (CASAN).

Para a análise econômica comparativa entre o sistema de recirculação individual e o sistema de recirculação proposto foram utilizados três indicadores: Valor Presente Líquido (VPL), Taxa Interna de Retorno (TIR) e o Período de retorno do investimento (Payback descontado).

\section{RESULTADOS E DISCUSSÃO}

O custo inicial total para a instalação do sistema de recirculação individual e proposto em todo o Edifício Palmas Central foi de, respectivamente, $\mathrm{R} \$ 61.013,78$ e $\mathrm{R} \$ 18.887,57$.

Os potenciais de economia de água dos cenários 1, 2 e 3 correspondem a, respectivamente, 5, 6 e 7\% do consumo diário de água para o condomínio Palmas Central, que é de 17,2 $\mathrm{m}^{3}$.

A Tabela 1 resume os resultados encontrados para os três indicadores econômicos para cada cenário de potencial de economia de água para os diferentes sistemas de recirculação analisados. 
Tabela 1 - Indicadores da análise econômica.

\begin{tabular}{|c|c|c|c|c|c|}
\hline Análise & Sistema & $\begin{array}{c}\text { Potencial de } \\
\text { economia de água }\end{array}$ & VPL (R\$) & $\begin{array}{c}\text { TIR (\% } \\
\text { por mês) }\end{array}$ & $\begin{array}{c}\text { Payback } \\
\text { descontado (meses) }\end{array}$ \\
\hline 1 & \multirow{3}{*}{$\begin{array}{c}\text { Recirculação } \\
\text { individual }\end{array}$} & 1 & $-69.205,24$ & $\mathrm{~N} / \mathrm{A}$ & $\mathrm{N} / \mathrm{A}$ \\
\hline 2 & & 2 & $-50.806,58$ & $-4,8$ & $\mathrm{~N} / \mathrm{A}$ \\
\hline 3 & & 3 & - 34.460,84 & $-1,0$ & $\mathrm{~N} / \mathrm{A}$ \\
\hline 4 & \multirow{3}{*}{$\begin{array}{c}\text { Recirculação } \\
\text { proposto }\end{array}$} & 1 & - 13.740,29 & $\mathrm{N} / \mathrm{A}$ & $\mathrm{N} / \mathrm{A}$ \\
\hline 5 & & 2 & $4.658,38$ & 0,7 & 96,7 \\
\hline 6 & & 3 & $21.004,11$ & 1,8 & 60,6 \\
\hline
\end{tabular}

Fonte: Os autores.

Analisando-se o comportamento do VPL em função do potencial de economia dos sistemas de recirculação foi possível obter o mínimo potencial de economia de água nos acionamentos da recirculação de modo que o VPL seja positivo, conforme ilustra a Figura 5. O mínimo potencial de economia de água para que os sistemas de recirculação individual e recirculação proposto tenham VPL maior que zero é de, respectivamente, 9,3 e 5,6\%.

Figura 5 - Relação entre VPL e potencial de economia de água.

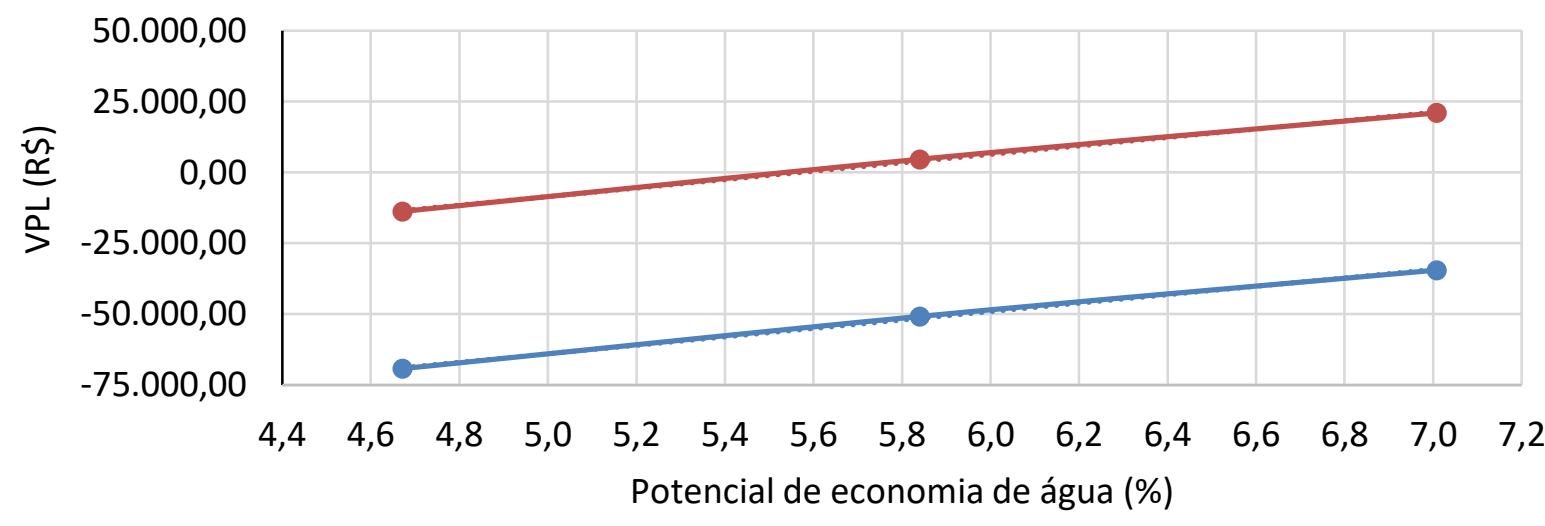

— Sistema de recirculação individualizada

$$
\begin{aligned}
& y=14875 x-138352 \\
& y=14875 x-82887
\end{aligned}
$$

Fonte: Os autores. 


\section{CONCLUSÕES}

A análise econômica do sistema automatizado proposto foi feita de modo comparativo com um sistema de recirculação individual tradicional. Verificou-se que para o mesmo edifício, o custo inicial total da instalação do sistema proposto pode ser $69 \%$ menor que o custo inicial da instalação dos sistemas de recirculação individual empregados atualmente.

Verificou-se que o mínimo potencial de economia de água para que os sistemas de recirculação individual e recirculação proposto tenham VPL maior que zero é de, respectivamente, 9,3 e $5,6 \%$.

Portanto, os sistemas de recirculação propostos com transmissão via radiofrequência são economicamente viáveis e podem ser uma alternativa para a redução de desperdício de água no setor residencial. Os sistemas propostos também se mostraram com maior viabilidade econômica quando comparados aos sistemas de recirculação individual tradicionalmente empregados.

\section{AGRADECIMENTOS}

Este trabalho foi realizado com apoio do CNPq, Conselho Nacional de Desenvolvimento Científico e Tecnológico - Brasil, por meio de bolsa de estudos ao primeiro autor.

\section{REFERÊNCIAS}

ASSOCIAÇÃO BRASILEIRA DE NORMAS TÉCNICAS. NBR5626: Sistemas prediais de água fria e água quente - Projeto, execução, operação e manutenção. Rio de Janeiro, 2020a.

ASSOCIAÇÃO BRASILEIRA DE NORMAS TÉCNICAS. NBR 13103: Instalação de aparelhos a gás: Requisitos. Rio de Janeiro, 2020b.

CHAGURI JUNIOR, J. J. Sistemas prediais de aquecimento de água a gás: parâmetros de dimensionamento e gerenciamento. 2009. Dissertação (Mestrado). Universidade de São Paulo, São Paulo, 2009.

DeOREO, W. B.; MAYER, P. W. Residential End Uses of Water: Study Update. Aquacraft, Inc. Water Engineering and Management. Denver, CO: AWWARF, 2014.

ELETROBRAS - Centrais Elétricas Brasileiras S. A., PROCEL - Programa Nacional de Conservação de Energia Elétrica. Pesquisa de Posse de equipamentos e Hábitos de Uso - Casse Residencial - Relatório Brasil. Rio de Janeiro, 2019.

GONÇALVES, O. M.; CHAGURI, J. J.; LANDI, F. D. N.; ILHA, M. S. O.; KAVASSAKI, Y.; HENRIQUES, A. M. J.; ISAAC, L. C. S. Desenvolvimento de tecnologias de substituição de aquecimento de água: programa de pesquisa e desenvolvimento tecnológico para o setor residencial. São Paulo, 1989.

IORIS, M. D; GHISI, E. Saving cold drinking water in residential hot water distribution systems. Revista Eletrônica em Gestão, Educação e Tecnologia Ambiental 2020; 24:e4.

IORIS, M. D; GHISI, E. Financial feasibility of implementing an automated system to save the cold potable water that would be wasted at the beginning of a hot shower. Urban Water Journal 2021; 18. doi: https://doi.org/10.1080/1573062X.2021.1949479. 
LUTZ, J. Estimating energy and water losses in residential hot water distribution systems. Lawrence Berkeley National Laboratory, University of California, Berkeley, 2005. Disponível em: https://escholarship.org/uc/item/4nj7m0q6. Acesso em: 07 jun. 2021.

LUTZ, J. Water and energy wasted during residential shower events: findings from a pilot field study of hot water distribution systems. Lawrence Berkeley National Laboratory, University of California, Berkeley, 2011.

SHERMAN, T. Disaggregating Residential Shower Warm-Up Waste: An Understanding and Quantification of Behavioral Waste Based On Data from Lawrence Berkeley National Labs. Evolve Technologies LLC. 2014.

WOOD, A.; D'ACQUISTO, J. Pilot Study for a Thermostatic Shower Restriction Valve. International Energy Program Evaluation Conference, Long Beach, 2015. Disponível em: http://docplayer.net/38354931-Pilot-study-for-a-thermostatic-shower-restriction-valve.html. Acesso em: 22 set. 2021. 